\title{
1. Introduction to international business education
}

You learn from foreigners that there is more than one path to a goal. Effective wealth creation demands that we use all the paths available to us. (HampdenTurner and Trompenaars 1993: 16, cited in Sinclair and Wilson 1999: 27)

International education around the world has grown exponentially in recent years. Tertiary education around the world is becoming 'internationalized': that is, there is an increasing mix of domestic and international students in classes. Many Western countries including the United States, the United Kingdom, Australia, New Zealand, Canada and South Africa provide education for significant numbers of foreign students from an increasingly diverse range of countries. 'Foreign' education is big business. Initially these students came from the region in which the university operated, that is, there was extensive movement between European countries, Britain attracted students from the Commonwealth where there were historical links, South Africa attracted students from other parts of Africa, and Australia and New Zealand's biggest source countries were in South East Asia.

As of 2007, the following are currently the top source countries for international students:

- USA: the top five source countries are India, China, South Korea, Japan and Canada. These five countries make up 46 per cent of the foreign students studying in higher education in the States.

- UK: the top five non-EU source countries are China, the USA, India, Malaysia and Hong Kong. These students make up 49 per cent of the non-EU foreign students.

- Australia: the top five source countries, that make up 56 per cent of the total foreign students include China, India, Malaysia, Hong Kong and Indonesia.

- Canada: the top five source countries make up 46 per cent of foreign students studying in Canada and include China, the USA, France, India and South Korea.

- New Zealand: the top five source countries make up 80 per cent of foreign student numbers in New Zealand and include China, South 
Korea, Japan, the USA and India. (http://aei.gov.au/AEI/Publications AndResearch.)

As can be seen from the above figures, despite the overall diversity of countries whose citizens travel to study, these five primary English language destinations are drawing from the same source countries, in particular, China and India. Even without considering the wide range of countries that make up the other ' 50 per cent', the diversity of culture, education system and worldview apparent within these primary source countries is considerable.

About 1.6 million students study outside their home country and of those over 500000 study in the US (Mazzarol and Hosie, cited in Avirutha et al. 2005). Education is the third-largest export in Australia (Marginson 2002) with over 100000 foreign students studying at Australian universities in 2000, and it is predicted that this will rise to over 500000 by the year 2022 (IDP 2002).

AEI (2006) provides the total numbers of international students for the main English-speaking provider countries:

- USA (2004) 572509.

- UK (2004) 325760 (214 190 non-EU).

- Australia (2004) 151799.

- Canada (2004) 70035.

- New Zealand (2004) 50213. (http://aei.gov.au/AEI/Publications AndResearch.)

One of the primary advantages of studying abroad is to learn a new culture and adapt to a new learning environment which offers real-life experiences (Avirutha et al. 2005). This is particularly important in business education where graduates will eventually work across a range of countries and cultures. Cross-cultural understanding has an important impact on business effectiveness in an increasingly global environment, and what is taught in the classroom needs to be relevant to all the students wherever geographically they follow their careers.

Despite this, and the fact that Australia, the US, the United Kingdom and many of the other host countries of international students are themselves extremely culturally diverse communities, business education remains essentially monocultural in form and Anglo-American in content (De Cieri and Olekalns 2001). The teaching and learning implications of such a large, very diverse international student population have yet to be addressed at most institutions of higher education. Not only are there an increasing number of international students on business programmes around the world, but they are coming from an increasingly diverse range 
of countries as can be seen above. For many of these students, their first language is other than English, though business classes, particularly at MBA and postgraduate levels, are traditionally taught in English. Their experience of tertiary education is often significantly different from that which they encounter at the 'Western' institutions. Their experiences are also different from each other. This raises challenges for teachers who are faced with sizeable classes made up of a combination of domestic and diverse international students.

These international students may want to understand the 'Western' way of doing things, but may not be familiar or comfortable with the processes used to facilitate learning (Pincas 2001). Business classrooms traditionally use a range of Western teaching and learning strategies that focus on critical analysis, oral discussion, problem solving and the possibility of multiple solutions using case studies and discussion groups that require active participation by the students, which many international students find unfamiliar. Every student comes to the classroom with a set of behaviours and characteristics that makes him or her unique (Ryan 2000; Jones 2005). But international students also come with their own expectations arising from the educational practices of their home communities. Their potential lack of participation in classroom activities puts constraints on classroom interaction and learning. It also means that nothing that they have to teach about their way of doing things, is learned.

Tertiary institutions have much vested in the successful education of all their students, including their increasing numbers of international students. Many tertiary institutions have become financially dependent on the substantial fee income from international students. As more and more institutions in more countries begin to compete for this lucrative student body, so recruitment by demonstrating quality and relevance becomes an increasing challenge. Around the world business schools are competing for accreditation as evidence of their quality. These accrediting bodies are concerned about the learning experience of all the students, and in the case of EQUIS (European Quality Improvement System of the European Foundation for Management Education (EFMD)) accreditation, the international nature of the students, staff and programme are essential to success:

Institutions that are accredited by EQUIS must demonstrate not only high levels of quality in all dimensions of their activities, but also a high degree of internationalisation. With companies recruiting worldwide, with students going to get their education outside their home countries, and with schools building alliances across borders and continents, there is a rapidly growing need to be able to identify those institutions in other countries that deliver high standards of education in international management. (www.efmd.org/html/Accreditations) 
Ranking of business schools and programmes is also on the increase and most use graduate feedback as an element. Not feedback from home-grown students only, but from all graduates. The learning experience of international students therefore becomes of critical importance - and all business students are seeking for their programmes to be relevant to their future career needs. This raises a range of challenges which move beyond the concerns of effective teaching and learning to institutional survival and success. It also means that effective teaching and learning and the role of those who facilitate learning are in the front line.

\section{THE INTERCULTURAL CLASSROOM}

The potential benefits of this student diversity are many (Cox and Blake 1991). Not only do international students bring significant revenue to the university but they also provide an opportunity for intercultural learning, for a sharing of knowledge and perspectives that could be so important for success in today's global business environment (Harding 2004). Yet research suggests that cultural engagement is largely unidirectional Australian (US and UK) students expect international students to adjust to them, not vice versa (cited in Marginson 2002). In classrooms with students from Europe, North and South America, Asia, India, Africa and Australia, the potential for intercultural understanding and skills development is enormous. But it will not happen without assistance. Many international students spend most of their time with other students who speak their language or who come from a similar cultural background. The host communities are not different in this respect. Therefore many international students, who come to study in a foreign country, learn about local business practices in the classroom but gain no practical experience of what local businesses, or local people, are like.

The attitudes and skills of teachers are of critical importance to the internationalization of the classroom (Anderson 2001). Their attitudes impact on providing effective learning experiences to all students in culturally diverse classrooms.

A number of questions then arise: what do the facilitators of learning, the teachers, lecturers and tutors, expect? What do they see as the benefits or disadvantages of this international diversity in their classrooms? What do they need to know and do to be effective in the classrooms of the twentyfirst century?

Many tertiary institutions include 'internationalization' as one of their objectives. But it is often unclear what that means. International student recruitment forms one aspect of internationalization, but will not 
necessarily increase the internationalization of the institution as many international students share little about their countries and live together with fellow nationals, so learn little about the country in which they study. The concept of 'Internationalization at home supports the view that much about internationalization can be taught at home' (Coyne 2003; Sandstrom 2003) but this requires the acknowledgement that internationalism requires a further examination of the learning environment, the curriculum, and the attitudes and abilities of teachers.

Attitudes to international students are varied. Many teachers see them simply as a source of revenue, believing that institutions are attracting international students as a means of enhancing the 'bottom line'. These teachers may adopt a strategy of exclusion - of denying that there is an issue. The difference remains invisible. The additional challenges brought about by international student concerns about being 'invisible' (after all they are paying a lot of money to be ignored) can also cause resentment among teachers as student-teacher ratios grow.

Others see that as students have chosen to study within these institutions, they must expect to be treated in the same way as all other students. No adjustment need be made either to their learning style or approach to business practice as they meet the general entry requirements. Many local students endorse and pressure teachers to adopt this approach. This leads to assimilation strategies-demanding homogeneity.

Many teachers recognize that if international students are to learn effectively, strategies need to be adopted that acknowledge their different backgrounds and learning experiences. This may lead to an integration approach, where students are helped to develop what are considered relevant competencies, attitudes and behaviours. This requires additional work on someone's part - either the teacher, or support services - which may be viewed as 'unfair' to domestic students, and more work for the teacher. However positive, it is still a deficit model, an assumption that students whose first language is not English, or who lack specific cultural knowledge, are in some way 'inferior' despite the fact that they may speak several languages, have travelled widely and be academically well qualified. This ethnocentric view of the world is now daily being challenged as we become aware that there are many different ways of being successful, and that often the key is to understand the 'rules' in any given context.

Very few teachers appear to have considered that international students are a resource that will enable all students to learn how to operate in a multicultural world (Dalglish 2006). The mutual adaptation model (Roosevelt 1996; Ballard and Clanchy 1997; Dalglish 2006) where difference is acknowledged and the difference forms the basis of mutual 
understanding - rather than a move to change to one particular perspective - is rarely implemented.

These four possible attitudes provide a model for understanding attitudes to international students. They reflect attitudes to those who are culturally and linguistically different. The particular view held by the lecturer or facilitator of learning is critical to internationalizing the curriculum as each person will be structuring the teaching and learning process based on a particular belief set (Cunningham 2005).

\section{THE PURPOSE OF THIS BOOK}

Few lecturers have been taught how to address the issues raised by the complex multicultural classroom (Cunningham 2005), whatever their personal perspective. That is the purpose of this book: to enhance teachers' understanding of the issues to be addressed in the global classroom and to provide practical strategies that will enhance the learning of all students, wherever they come from, and assist the teachers to overcome their frustrations with such a complex work environment and gain greater satisfaction from their classroom experiences.

Most teachers care about their students' learning, wherever those students may come from. They often have a passion for their discipline and want to communicate their enthusiasm to their students. Cultural diversity complicates this process, but it is possible to change this apparently insurmountable challenge to an opportunity for a more rewarding teaching and learning experience for all concerned.

\section{STRUCTURE OF THE BOOK}

The book is divided into two parts - the first part explores the 'what' and the 'why' of teaching in the global business classroom, and consists of five chapters addressing such issues as understanding intercultural education, culture shock, learning and cross-cultural communication. The second part addresses the 'how'. It provides practical guidance for teachers in the primary areas of concern in university business education: curriculum design, lecturing, classroom participation, working in groups, using case studies, assessment and distance learning. 


\section{REFERENCES}

aei.gov.au/AEI/PublicationsAndResearch, 'International student numbers', accessed July 2006.

Anderson, Mary (2001), 'Cross-cultural communication in the global classroom: issues and implications', Melbourne: Monash University.

Avirutha, Anupong, Mai X. Bui, Geraldine H. Goodstone, Kenya Reid, et al. (2005), 'Current overview and future of business higher education', Futurics, 29 $(1 / 2)$.

Ballard, Brigid and John Clanchy (1997), Teaching International Students, Sydney: IDP Education Australia.

Coyne, David (2003), 'Internationalisation at home and the changing landscape', Internationalisation at Home Conference, Malmo University, April.

Cox, Taylor H. and Stacy Blake (1991), 'Managing cultural diversity: implications for organisational competitiveness', Academy of Management Executive, 5 (3).

Cunningham, Donna J. (2005), 'Teaching multiculturalism in an age of terrorism: a business perspective', Cross Cultural Management, 12 (2).

Dalglish, C. (2006), 'The international classroom: challenges and strategies in a large business faculty', International Learning Journal, 12 (6): 85-94.

De Cieri, Helen and Mara Olekalns (2001), 'Workforce diversity in Australia: challenges and strategies for diversity management', Melbourne: Monash University.

Hampden-Turner, C. and A. Trompenaars (1993), The Seven Cultures of Capitalism, New York: Doubleday.

Harding, S. (2004), International at QUT, Brisbane: QUT, June.

IDP Education Australia (2002), Global Student Mobility, Sydney: IDP.

Jones, Lisa A. (2005), 'The cultural identity of students: what teachers should know', Kappa Delta Pi Record, 41 (4).

Marginson, Simon (2002), 'The phenomenal rise of international degrees down under', Change, 34 (3): 34-43.

Nahal, Anita (2005), 'Cultural collisions', Diverse Issues in Higher Education, 22 (20).

Pincas, Anita (2001), 'Culture, cognition and communication in global education', Distance Education, 22 (1): 30-51.

Roosevelt, Thomas R. Jnr (1996), Redefining Diversity, New York: American Management Association.

Ryan, Janette (2000), A Guide to Teaching International Students, Oxford: OCSLD.

Sandstrom, Shirin (2003), 'Networking for internationalisation at home in nursing education', Internationalisation at Home Conference, Malmo University, April.

Sinclair, Amanda and Valerie Britton Wilson (1999), The Culture-Inclusive Classroom, Melbourne: Melbourne Business School, University of Melbourne.

www.efmd.org/html/Accreditations, accessed July 2006. 